\title{
TERRESTRIAL LASER SCANNING AND DIGITAL PHOTOGRAMMETRY FOR HERITAGE CONSERVATION: CASE STUDY OF THE HISTORICAL WALLS OF LAGOS, PORTUGAL.
}

\author{
L. Mateus ${ }^{1}$, J. Fernández $^{1}$, V. Ferreira ${ }^{1}$, C. Oliveira ${ }^{1}$, J. Aguiar ${ }^{1}$, A. S. Gago ${ }^{2}$, P. Pacheco ${ }^{1}$, J. Pernão ${ }^{1}$ \\ ${ }^{1}$ CIAUD, Lisbon School of Architecture, University of Lisbon, Lisbon, Portugal (lmmateus, jorgefernandez, victor, 20130244, \\ jaguiar, apacheco,jnpernao)@ fa.ulisboa.pt \\ ${ }^{2}$ CERIS, IST, University of Lisbon, Av. Rovisco Pais 1, Lisbon, Portugal - antonio.gago @ tecnico.ulisboa.pt
}

KEY WORDS: Conservation, Laser Scanning, Photogrammetry, Heritage Values, Authenticity

\begin{abstract}
:
Conservation planning is a complex process involving a wide range of agents such as architects, engineers, conservators and archaeologists. Their integrated inputs contribute to the definition of criteria for the conservation project and the conservation strategy. In this process, graphical documentation is a common denominator to all involved areas-of-expertise. It provides the basis for the dialog between agents coming from different fields of knowledge that often don't speak the same technical language nor share the same codes. The way this dialog can be improved through documentation is the main motivation of our study.

In this paper we analyze the requirements of digital documentation in Cultural Heritage $(\mathrm{CH})$ conservation strategies, and we tackle the fundamental role of photogrammetry and terrestrial laser scanning (TLS), and integrated implementation throughout the several steps, from the fieldwork to the conservation planning for $\mathrm{CH}$ sites. The described process is demonstrated through the case study of 'the conservation project of the historic walls of Lagos', in south Portugal.

After introduction and related work, the study is structured in four main sections. In the second section, we present the case study and conduct an analysis of existing data and preliminary synthesis of heritage values related to the historic walls of Lagos. Second section corresponds to an overview of the project workflow. This spans from recording and documentation, considering geometry, colour, light, materials and degradation forms; to their analysis and diagnosis, resulting in criteria and guidelines for the intervention actions. Third section emphasises on how the simultaneous use of photogrammetry and TLS in the documentation process, and its relationship with other methods and techniques, introduces a distinctive character in the conservation project. Fourth section is about the documentation process with photogrammetry and TLS. Finally, fifth section focus in the analysis and architectural project.
\end{abstract}

\section{INTRODUCTION AND RELATED WORK}

In Conservation and Restoration of $\mathrm{CH}$ sites, graphical documentation is an essential mean to record and understand current physical state of assets, to plan the conservation project's decisions, to document the works done and to disseminate the results. For these purposes, photogrammetry and TLS are becoming recognized and accepted standard methods. These technologies provide a never-before reached accuracy and completeness of data, they can overcome difficult geometric configurations allowing an almost continuous description of the site features, they dramatically reduce time and costs. They facilitate the production of 3D realistic models although sometimes plans, sections and elevations are considered enough (Alshawabkeh et al., 2011) (Remondino et al., 2010). At the same time, these tools are increasingly becoming accessible to non-expert users, specially in the field of Architecture, Archaeology and Natural Sciences.

The integration of photogrammetry requirements and computer graphics solutions have burst the number of user friendly and cost-effective software, reinforcing the democratization of these techniques especially to conservation professionals (PeñaVillasenín et al., 2017) (Remondino et al., 2010) (Remondino et al., 2014).

This bridged the traditional gap between geospatial data providers and users as it can help to bring the former to the initial stages of the documentation process. This is a cornerstone in our understanding of the role of documentation in Heritage conservation. The use of $\mathrm{CH}$ documentation cannot be limited to a mere production of maps, but as a source of information and feedback along the entire conservation and restoration process.

In $\mathrm{CH}$ sites, where it is common to find complex geometries with many different configurations, the combination of the adequate methods maximizes the chances to achieve the desired results. TLS and photogrammetry must be understood as complementary methods rather than competitors. On the one hand, TLS is an efficient method to create a geometrically robust base for 3D modelling. However, its main limitation is to be earth-bound. For example, high elements of façades or inaccessible roofs tend to be poorly documented from ground stations. On the other hand, photogrammetry is more flexible. It is easy to mount a camera on a mast or in a drone to record the hard-to-reach areas.

Traditionally conservation agents (architects, conservators) rely mostly on 2D documentation to conduct conservation projects (El-Hakim et al., 2007). In this research we demonstrate that whilst this is still true, the potential of $3 \mathrm{D}$ data is recognized because it allows a the 2D documentation on demand, it allows to clarify features of the site through the models inspection, and

\footnotetext{
* Corresponding author
} 
to works as a node for the dialog between the conservation professionals

\section{HISTORIC WALLS OF LAGOS - EXISTING DATA AND HERITAGE VALUES}

Nowadays, the historic walls of Lagos consist of several layers from different periods merged with existing buildings. In some parts along its $3 \mathrm{Km}$ perimeter, the walls no longer exist or are embedded within the buildings. The conservation project here discussed is limited to approximately $1.2 \mathrm{Km}$ of the XVIth century bulwark (fig. 1). This portion is composed by seven bastions connected by masonry walls.

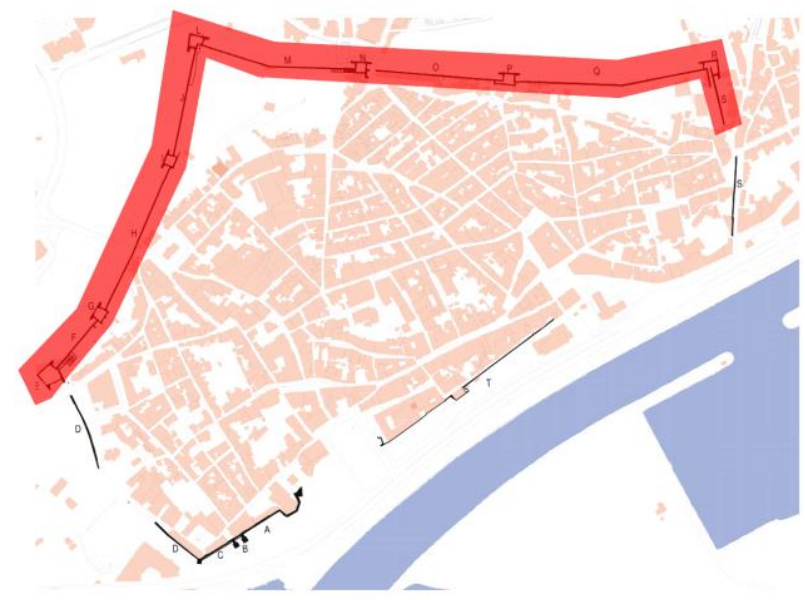

Figure 1. Historic walls of Lagos (the limits of the conservation project are highlighted in red)

The plan of the modern walls is attributed to the architect Manuel Arruda in the mid XVIth century. The historic walls are listed as national monument since 1924. During the sixties of last century, the former "Direcção Geral dos Edifícios e Monumentos Nacionais" conducted works that originated shaped the current configuration of the medieval walls (Pereira, 2017).

The seven bastions are (from left to right in figure 1): i) "Baluarte da Porta da Vila", ii) "Baluarte do Coronheiro", iii) "Baluarte da Gafaria", iv) "Baluarte das Freiras", v) "Baluarte da Porta dos Quartos", vi) "Baluarte do Paiol", and vii) "Baluarte do Jogo da Bola".

We endorse the idea that the path for the conservation project starts to be paved in the early stage of the process where existing data and knowledge is processed. Following this principle, we gathered, analysed and synthesized existing information from two mains sources: i) the SIPA (Architectural Heritage Information System) database (http://www.monumentos.gov.pt), and ii) the Portuguese Army's Historical Archive, where historic cartography, imagery, and written documents are available. We also consulted several academic studies of the historical Walls coming from several disciplines: History, Archaeology, Architecture and Art. Data synthesis defined the main values to be considered in conservation strategy: i) layers of military history because these were the first modern fortified walls in Portugal, highly characterized by the pyroballistic paradigm, which implied the creation of large platforms where all the artillery fire power was settled, and ii) the presence in the landscape as an urban structural element. These platforms were extended with high walls, allowing firing parallel to the curtain walls protecting them from enemy. Each of the platforms corresponds to a bulwark. The bulwarks are connected with walls without patrol-paths other defensive devices. The outline of the walls also conditioned the urban sprawl of the city that can be seen in the configuration of some of the streets (Pereira, 2017).

\section{THE INTERVENTION PLANNING WORKFLOW - FROM DOCUMENTATION TO THE PROJECT PRINCIPLES}

After the first step, it became clear that the existing data and knowledge were not enough to ground the basis for the conservation project. Old cartography was outdated and incomplete, and it was noticed that different elements were not congruent. Moreover, there was lack of information such as textures and colours, relevant for the conservation strategy. Therefore, it was decided to conduct a three-dimensional survey of the walls and bastions. This 3D survey, being itself a new document, was used as: i) a support for the representation of the new 2D documentation such as plans, sections and elevations, ii) a helpful tool to support analyses of various types, such as inspection of materials and state of conservation, and iii) the basis for new design interventions, aiming at making the site accessible to all the community, protecting and enhancing the historical values.

The strategy to tackle the survey started with the subdivision of the wall in seven sections determined by the bastions. One bastion and the contiguous walls composed each section. For each of these we developed plans, sections, elevations and orthoimages from the 3D models produced. Both 3D models and subsequent outputs were shared with all team members to develop transversal/multidisciplinary analysis on colours, materials, state of conservation, as well as spatial and organizational analysis concerning the architectural and urban characteristics of the site. The conducted cross analysis reinforced the sense of persistence in the urban landscape throughout time. Another significant conclusion was the authenticity marked by an original materiality, which is still present in many areas. These, together with the historical value, were defined as key factors for the conservation project. Based on these findings, the criteria for the conservation project were: i) to keep the original materiality as much as possible with especial attention to the military layers, ii) to make accessible relevant areas, which cannot be visited today, and in this way engaging people and heritage, and iii) restore an idea of architectural unit enabling an awareness and deeper understanding of the architectural and landscape values present on this site.

\section{PHOTOGRAMMETRY AND LASER SCANNING AS COMPLIMENTARY SURVEYING TOOLS}

In this section we discuss the role that photogrammetry and laser scanning played in this process. Two field campaigns on site where planned to collect all relevant data. These took place on May and October,2018.

Some unexpected difficulties were experienced during the fieldwork:

- Rough terrain with significant slopes near parts of the wall,

- Profuse vegetation interrupting direct vision to the site, 
- Engineering work in nearby areas changing the configuration of the terrain between one first and second campaign,

- $\quad$ Large amount cars parked nearby the walls.

- $\quad$ Private properties adjacent to the significant portions of walls, making impossible to access them from the ground

- Seagulls in nesting periods during the first campaign, turning the birds extremely aggressive against the drone and operators. It was only possible to conduct the aerial captures in the second campaign.

The survey was done using three complementary methods operating simultaneously: GPS positioning, TLS survey and photogrammetry capture.

For control data it was used GPS positioning (fig. 2).

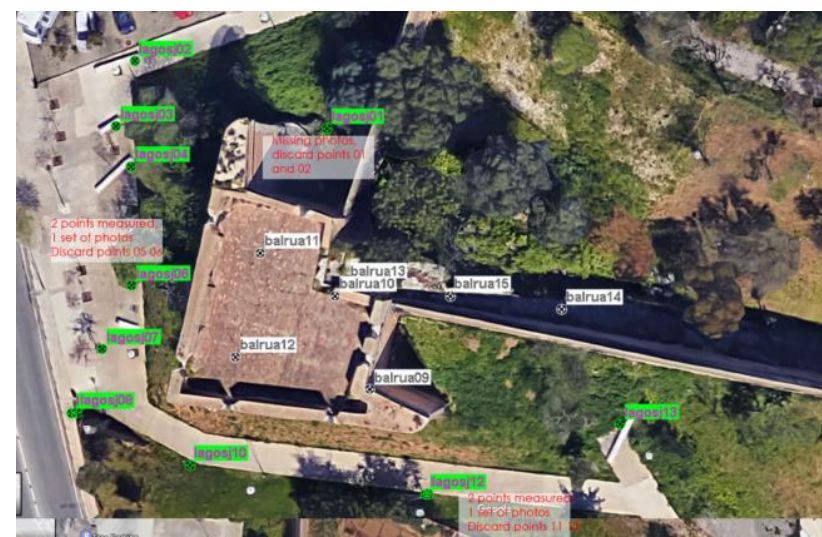

Figure 2. GPS control points surveyed in "Baluarte das Freiras"

Reference points were set on natural features of the site that could be easily identified in laser scanning point clouds and in photographs. It was collected a total of 57 GPS points.

A TLS survey was done in the accessible areas from ground stations (fig. 3) which had public access.

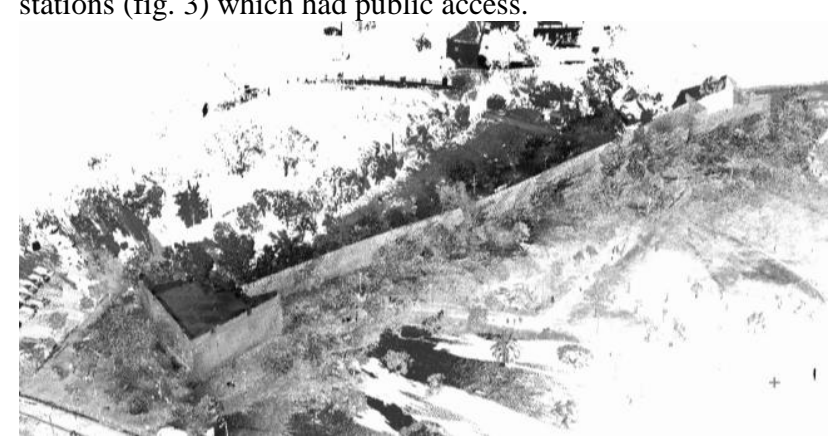

Figure 3. Partial view of the laser scanning survey of "Baluarte das Freiras"

It was used the Faro Focus 3D S120 phase-based scanner. For the registration of the point clouds, it was considered a 'cloud to cloud' strategy implemented in Scene software. In areas with large incidence of vegetation, the target-based registration was the way to ensure good results. Scanning was done without colour capture to reduce the fieldwork time and with the guarantee of registering a solid RGB info from the photogrammetric survey.

According to the walls' morphology and considering the topographic conditions of the site, it was decided to organize the TLS survey in six clusters. Only the bastions of "Gafaria" and "Freiras" were merged in the same cluster. It was collected a total of 182 scans. Table 1 summarizes the TLS stations and GPS point surveyed per cluster.

The combination of GPS and laser scanning provided geometrically accurate models in a global coordinate system. However, in terms of geometry and radiometry information, the models were incomplete. To record colour information and to fill the geometric gaps in the TLS survey, it was conducted a photogrammetric campaign using both terrestrial and dronebased images. As previously described, the inner side of the wall has difficult access because current constructions are contiguous, and the access is private. Therefore, the use of drone becomes essential to gather images of those inaccessible areas.

\begin{tabular}{|l|c|c|}
\hline Bastion name & $\begin{array}{c}\text { N. of } \\
\text { scans }\end{array}$ & $\begin{array}{c}\text { N. of GPS } \\
\text { points }\end{array}$ \\
\hline Porta da Vila & 29 & 13 \\
\cline { 1 - 1 } Corunheiro & 8 & \\
\hline Gafaria & 83 & 6 \\
\cline { 1 - 1 } Freiras & & 20 \\
\hline Porta dos Quartos & 32 & 8 \\
\hline Paiol & 15 & 5 \\
\hline Jogo da Bola & 15 & 5 \\
\hline & 182 & 57 \\
\hline
\end{tabular}

Table 1. Number of scans and GPS points collected

In order to fill the void areas in the laser scanning models and gather a comprehensive colour information, two types of photogrammetric models were generated: i) global lowresolution models covering the whole area of study with GSD $20 \mathrm{~mm}$ (fig. 4), and ii) partial high-resolution models targeting single units with GSD 5mm (fig. 5).

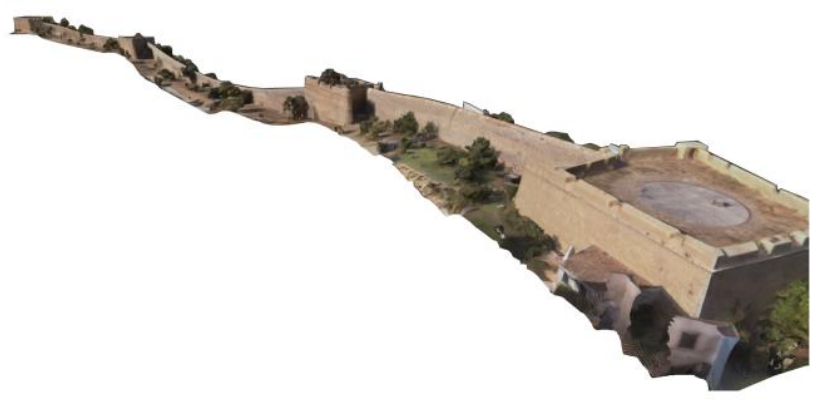

Figure 4. Partial view of the low-resolution photogrammetric model

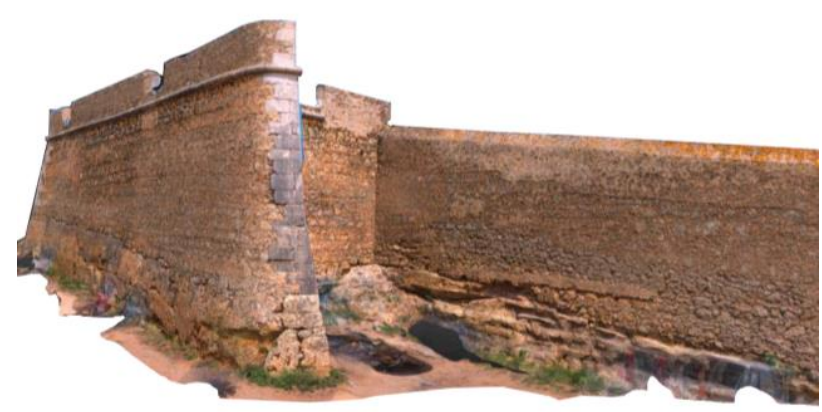

Figure 5. Partial view of the high-resolution photogrammetric model of "Baluarte do Jogo da Bola"

The low-resolution quickly-produced models, was intended to serve as basis features and proportions understanding, and for 
planning data extraction for the analysis to be performed using the other models.

Its ability to be accessible and manageable online (we used the online repository Sketchfab), also allowed a continuous input from the several actors involved in the project.

The high-resolution models proved to be powerful means of inquiry about the built environment. They were considered not just an intermediate step to allow the production of drawings or images but a source of information themselves that is not possible to depict in traditional 2D data.

\section{ANALYSIS AND PROJECT}

For each bulwark it was produced a top view, together with front views of all the vertical surfaces. Developed models where used to produce a representative family of 2D products (plan, sections, and elevations). Production process was automatized to develop one true-ortho image from top view, and true-orthos from each vertical plane (two in the case of wall segment, and from six-eight om the case of bulwarks).

Whenever there existed TLS and photogrammetry data, both sources were used to generate the images. Otherwise, only photogrammetry was used. These $2 \mathrm{D}$ pixel-based documents were manually vectorized, constituting the based to produce CAD drawings. Figures 6 and 7 exemplify the result of that process for "Baluarte da Porta dos Quartos".

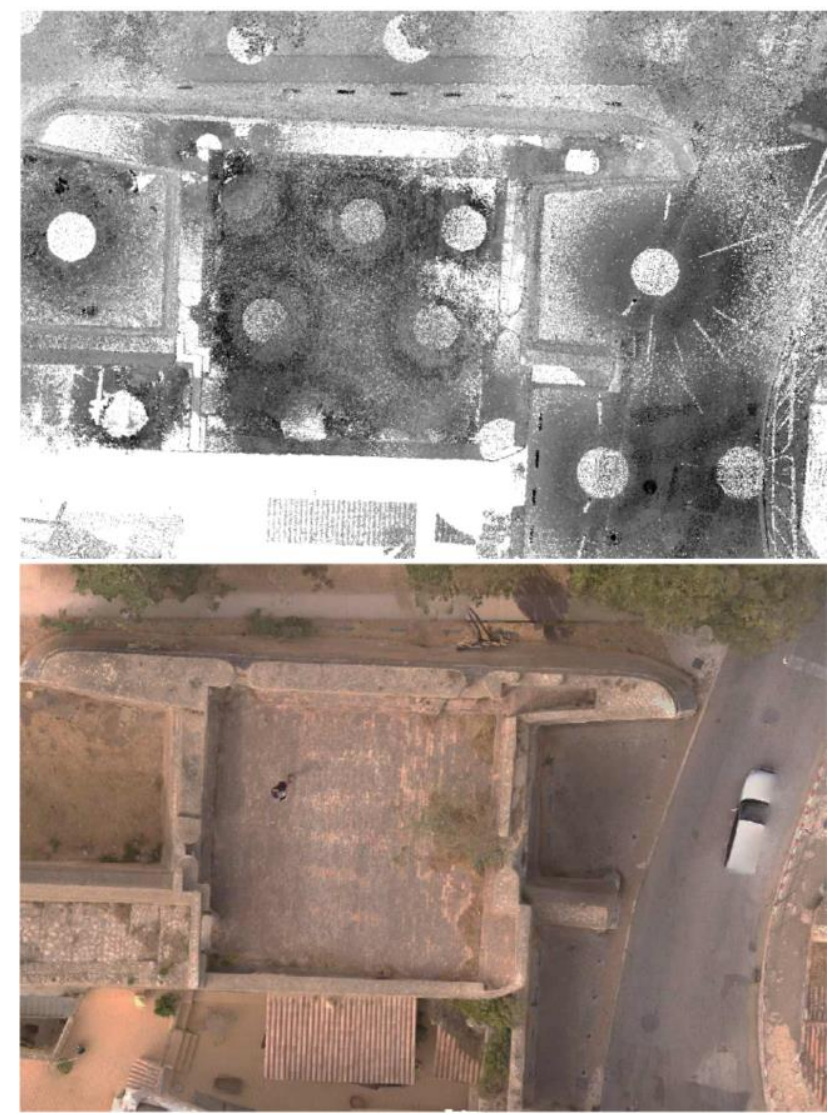

Figure 6. Top view orthoimages of "Baluarte da Porta dos quartos" from TLS (top) and photogrammetry (bottom)

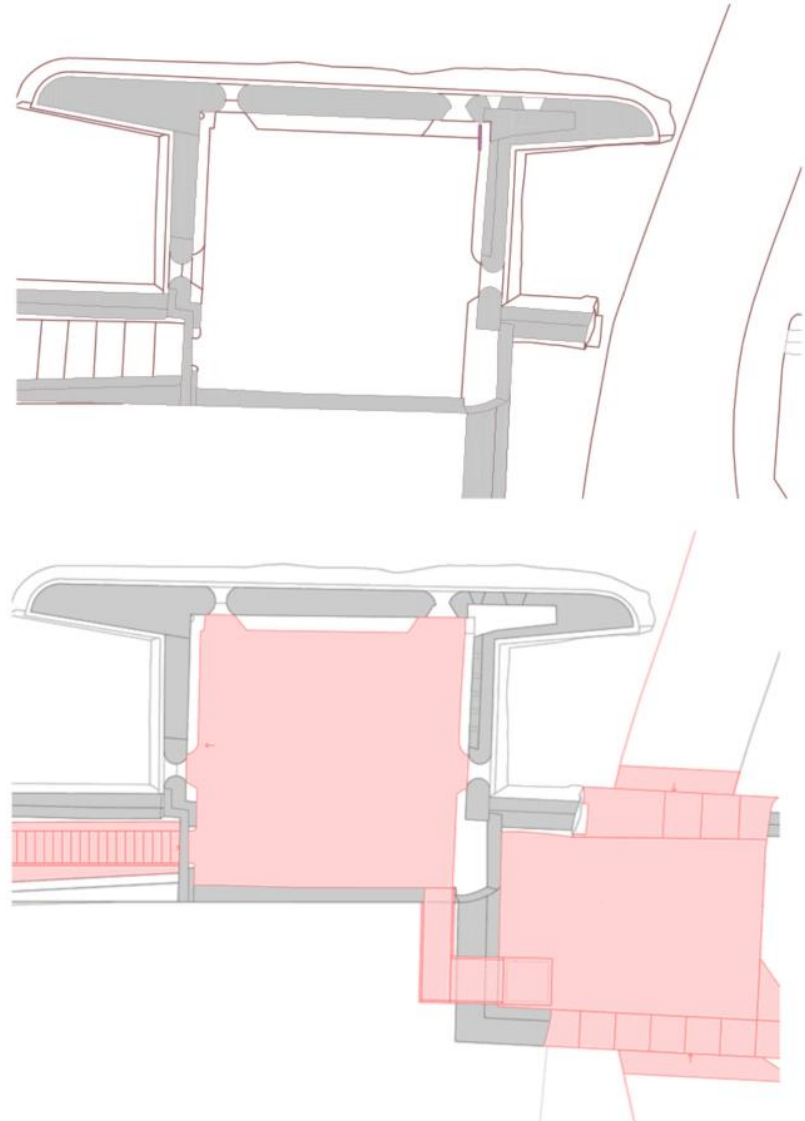

Figure 7. Top view CAD drawings of "Baluarte da Porta dos quartos"; survey (top) and design intentions (bottom)

These documents were the basis to understand the current state of the site in terms of degradation (fig. 8), constructive techniques, materials, accessibilities, colours, and architectural and urban structure.

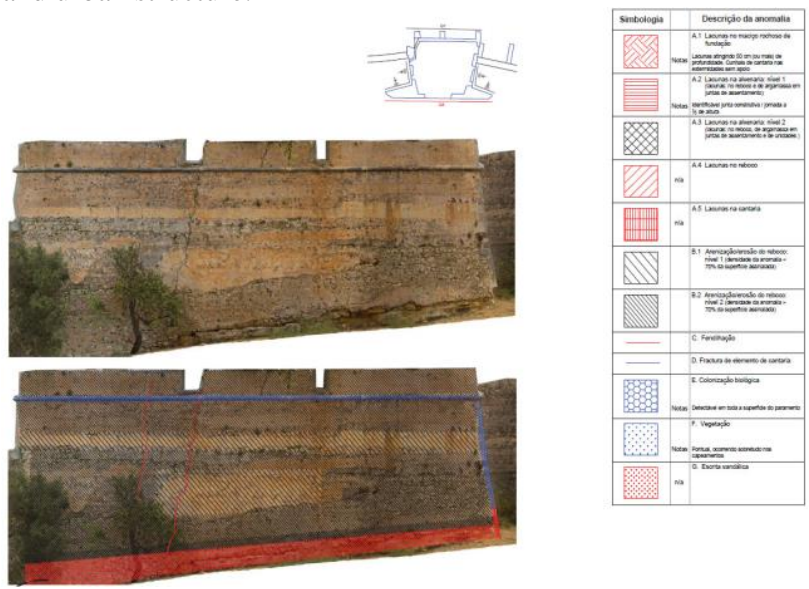

Figure 8. Example of the state of conservation' documentation of "Baluarte do Corunheiro"

Based on the analysis process, six main action packages were defined:

- Adequation of landscape to highlight point-of-interest

- Signalling footprint of those parts of wall that no longer exist

- Communication project with historical and functional information 
- Accessibility to bulwarks and platforms, including

- Paving spaces of bulwarks

- Consolidation and strict conservation of bulwarks, platforms, walls, doors and passages

At this point, it is worth mentioning to what extent it was relevant, to the analysis and project, to have used photogrammetry and laser scanning as methods to gather data and to generate information.

As previously mentioned, the integrated use TLS and photogrammetry allowed us to record the site and develop specific analysis along the conservation project. The main advantages exploited from each technology are summarized below.

Advantage from TLS models:

- precise geometric measurement of areas to determine the cost of new materials

- verification and analysis on walls' deformations

- confirmation and accurate measuring of cracks and gaps in the mortars, enabling to estimate volumes of filling materials

- $\quad$ raising the overall level of confidence when testing design hypothesis, which prevent successive visits to the site.

Advantage from Photogrammetric model:

- complementing TLS models filling existing gaps

- continuous reading the surfaces in terms of constructive techniques, materials and state of conservation

- $\quad$ systematic queries about the site and its qualities replacing, to some extent, the real site

- $\quad$ virtual access and multiple actor's discussion over an online and easy-accessed repository

- fast 3D data availability

Alongside with the visits to the site, the photographic database (used for photogrammetry), also complemented input data to accurately characterize the materials and constructive techniques. Especially aerial images were a key resource to show inaccessible areas, and to plan ground campaigns.

About the above-mentioned action packages, TLS and photogrammetric data played a key role in the last three, which correspond to more direct and physical interventions.

\section{CONCLUSIONS}

The use of photogrammetry and TLS as complementary methods allowed an almost continuous recording of objects with a high level of accuracy. This not only provides solid documents for conducting conservation projects, but also increases the level of confidence on design decisions. Compared with traditional method, our proposed integration decreases the errors by interpretation and increases the accuracy and resolution of final models. As exposed in this paper, these techniques can work in parallel, which represent a considerable advantage in terms of time cost at fieldwork. Their integration minimizes limitation of both technologies. While aerial photogrammetry can fill the gaps in TLS survey and enhance models with real colour, TLS data can provide control data for photogrammetry and assist in the camera alignment process. Through our case of study, it was demonstrated that these methods represent a valuable asset in the architect and conservator toolbox. Combining both methods maximize accuracy in terms of geometry and radiometry. Moreover, since authenticity as a qualifying factor of heritage values is related with the truthfulness of the information sources, these models also support the conservator's ability to recognize and identify architectural artefacts and landscape's values.

\section{ACKNOWLEDGEMENTS}

The research leading to these results has been partially funded from the Research and Innovation Framework Programme (Marie Curie Actions) of the European Union's Horizon 2020 Framework Programme H2020-MSCA-IF-2016, project 3DSMoHC no. 747046 .

The authors also want to thank to the Municipality of Lagos for the support given during the work.

\section{REFERENCES}

Alshawabkeh, Y., Douglas, K., Matarya, M., Khrisat, B., 2011. Combined Photogrammetric Techniques and Computer Vision: 2D-3D Recording of Gharissa, Jordan. In: Journal of Architectural Conservation, 17:2, pp. 77-92, DOI: 10.1080/13556207.2011.10785090.

El-Hakim, S., Gonzo, L., Voltolini, F., Girardi, S., Rizzi, A., Remondino, F., Whiting, E., 2007. Detailed 3D Modelling of Castles. In: International Journal of Architectural Computing, Vol. 5 Issue 2, pp. 199-220.

Peña-Villasenín, S., Gil-Docampo, M., Ortiz-Sanz, J., 2017. 3D Modeling of Historic Façades Using SFM Photogrammetry Metric Documentation of Different Building Types of a Historic Center. In: International Journal of Architectural Heritage, 11:6, pp. 871-890, DOI: 10.1080/15583058.2017.1317884.

Pereira, D., 2017. A Evolução Urbanística de Lagos (Séculos $X V$-XVIII). Faro: DRC Algarve

Remondino, F. \& Poli, D., 2014. Back to the future Il ritorno della fotogrammetria. In: GEOmedia, Vol. 18 Issue 2, pp. 6-8.

Remondino, F., Rizzi, A., 2010. Reality-based 3D documentation of natural and cultural heritage sitestechniques, problems, and examples. In: Applied Geomatics, Vol. 2 Issue 3, pp. 85-100. 